\title{
Rat Coronavirus (RCV): A Prevalent, Naturally Occurring Pneumotropic Virus of Rats ${ }^{1}$
}

\author{
By \\ J. C. Parker, S. S. Cross, and W. P. Rowe ${ }^{2}$ \\ Microbiological Associates, Inc., Bethesda, Maryland, U.S.A. \\ With 4 Figures
}

Received January 8, 1970

Summary

A new virus isolated from the lungs of rats is prevalent in colony reared and wild rats and induces a fatal pneumonitis in newborn rats. The virus, designated as rat coronavirus (RCV), exhibits properties representative of the coronavirus group: characteristic surface structure, particles somewhat variable in size averaging approximately $90 \mathrm{~m} \mu$, apparent RNA content, essential lipid, heat sensitivity, and a close serologic relationship with the mouse hepatitis virus complex. RCV grows well in primary rat kidney cell cultures, exhibits a pathognomonic type CPE, and produces a complement fixing antigen which is sensitive for detection of antibody and useful in sero-epidemiologic studies.

\section{Introduction}

Members of a newly recognized group of viruses, the coronaviruses (1), include avian infectious bronchitis virus (IBV), the mouse hepatitis virus (MHV) group, and a number of virus strains recently isolated from the upper respiratory tract of man $(9,11)$. All members of the coronavirus group share certain basic characteristics which include: a pleomorphic particle ranging in size from $76-250 \mathrm{~m} \mu$ with characteristic club-shaped surface projections, sensitivity to lipid solvents and heat, and a ribonucleic acid content $(1,9,11)$.

HARTLEY et al. (7) reported the presence of MHV reactive antibody in human sera and rat sera but could not account for the agent(s) responsible. Recent studies by McIrTosh et al. (11) accounted for this reactivity in human sera by demonstrating antigenic relationships between the IBV-like viruses from humans and the MHV group. This report accounts for the MHV reactivity in rat sera reported by HARTLEY et al. (7), by describing the isolation and characterization of a new coronavirus isolated from the lungs of normal rats which is distinct from MHV but has a serological relationship to MHV.

\footnotetext{
1 Supported by Public Health Service Contract No. SA-43-67-700 with the National Cancer Institute, National Institutes of Health, Bethesda, Md., U.S.A.

2 Laboratory of Viral Diseases, National Institute of Allergy and Infectious Diseases, National Institutes of Health, Bethesda, Md., U.S.A.
} 


\section{Materials and Methods}

\subsection{Cell Cultures}

Primary rat kidney cell cultures (RKCC) were prepared from germfree Fischer rats (Charles River Breeding Laboratories [CRBL], North Wilmington, Mass., U.S.A.) $4-8$ weeks of age. This colony has been monitored serologically over a period of several years and has never shown antibody to MHV. Each kidney was decapsulated and the medulla removed and discarded. The remaining cortex was minced, washed $4 \times$ in cold Eagle's basal medium with Earle's salts (EBME) containing 100 units penicillin and $100 \mathrm{~kg}$ streptomyein per $\mathrm{ml}$, and trypsinized $(0.25 \%$ trypsin in EBME) $16-20$ hours at $4^{\circ} \mathrm{C}$. Tube cultures were planted. with $5 \times 10^{5}$ cells in $1 \mathrm{ml}$ growth medium and $32 \mathrm{oz}$. or $4 \mathrm{oz}$. flasks were planted with $2 \times 10^{7}$ in $40 \mathrm{ml}$ and $5 \times 10^{6}$ in $5 \mathrm{ml}$ growth medium respectively. Cultures were incubated at $37^{\circ} \mathrm{C}$ in a humidified atmosphere containing $5 \% \mathrm{CO}_{2}$ until cell monolayers were confluent. Medium for cell growth consisted of Eagle's minimum essential medium (EMEM), $15 \%$ fetal bovine serum (FBS), $2 \mathrm{mM}$ L-glutamine and $0.1 \mathrm{~mm}$ non-essential amino acids (media were purchased from Microbiological Associates, Inc., Bethesda, Md., U.S.A.). Serum was reduced to $2 \%$ for maintenance. Cell cultures usually were confluent in 5 days and were used immediately since the susceptible epithelial cell type apparently persists only for about one week. For virus inoculation, cell cultures were rinsed twice with EMEM and overlaid with the virus suspension which contained $50 \mu \mathrm{g}$ of DEAE dextran (Pharmacia) (10). Cultures were incubated at room temperature for 1 hour and the monolayers rinsed twice with EMEM after which the cultures were placed on maintenance medium and incubated at $37^{\circ} \mathrm{C}$.

\subsection{RCV Antigen and Antiserum}

For preparation of complement fixing (CF) antigen, confluent monolayers of RKCC in $32 \mathrm{oz}$. flasks were inoculated with approximately $10^{5.0} \mathrm{TCID}_{50}$ doses of RCV, and the cells harvested in one tenth the supernatant fluid (17). The first appearance of CF antigen coincided with the appearance of cytopathic effects (CPE) 18 hours after infection. Maximum CF titers were obtained from 21 to 27 hours when CPE was progressing from 25 to $75 \%$. CF antigen titers of 1:8-1:16 were routinely produced. Antigen titers in the cell-free supernatant fluids were usually 2 - to 4 -fold less than the cell-packs. In seroepidemiologic studies, 8 to 16 antigen units were used.

Antiserum was prepared in weanling Fischer rats by 3 intraperitoneal inoculations $\left(10^{5}\right.$ TCID $_{50}$ each) at one week intervals and bleeding one week later. Antiserum prepared in this manner had a CF antibody titer of $1: 1280$ and was also suitable for indirect fluorescent antibody and neutralization tests.

\subsection{Murine Viruses}

Preparation of a polyvalent MHV CF antigen with MHV strains, A-59, JHM, MHV-1, and MHV-S has been deseribed (13). Polyvalent MHV mouse antiserum was prepared by a weekly intraperitoneal inoculation with each strain in the following order; MHV-1, MHV-S, JHM, and A-59 followed by a fifth inoculation with a polyvalent antigen. One week later the animals were bled for serum. The sources, preparation, and serological use of other murine virus reagents used in this study are given elsewhere (13).

\subsection{Serologie Techniques}

Complement fixation and hemagglutination techniques, described elsewhere (13), were performed using the microtiter system.

\subsection{Electron Microscopy}

Electron microscopic studies were performed by Dr. Mina Lee Vernon, Microbiological Associates, Ine. RKCC monolayers in $32 \mathrm{oz}$. flasks were inoculated with $10^{5}$ TCID $_{50}$ of virus and supernatant fluids harvested or cell-packs prepared when CPE involved 50 to $75 \%$ of the cell monolayer. Supernatant fluids were centrifuged at $100,000 \times g$ for 90 minutes in a $S W-30$ rotor of a Spinco model $L$ ultracentrifuge and pellets resuspended in $2 \%$ phosphotungstic acid for negative contrast staining. For 
thin sections, cell-pack pellets were fixed in $2 \%$ glutaraldehyde and postfixed in $1 \%$ Dalton's chromate osmium fixative. Pellets were embedded in Epon 812 araldite mixture. Thin sections were cut on an LKB ultramicrotome and stained with uranyl acetate and Fahmy's lead citrate. All specimens were examined with a Hitachi $11 \mathbf{E}-1$ microscope at a magnification of $50,000 \times$.

\subsection{Animals}

Fischer rats or Webster Swiss mice used for virus inoculation studies were purchased from National Laboratory (NL) Animal Company, Creve Coeur, Mo., U.S.A. Since 1964 this colony has been monitored serologically, and at no time has shown evidence of infection with any of the commonly occurring viruses of mice or rats.

All animals used in this study were housed in filter-top cages, and all bedding and diet was steam sterilized. Apples were used as the water source. A single cubicle was used for all animals. This cubicle, which did not contain other animals or experiments, was under positive pressure to surrounding areas and was located in a building separate from the virus laboratory; air was not recirculated. Techniques and procedures were used to minimize the hazards of accidental contamination by RCV or other adventitious agents.

\section{Results}

\subsection{Prevalence}

Prior to isolation of $R C V$, a serologic survey was conducted to determine the prevalence of MHV-reactive CF antibody in normal rats. A polyvalent MHV cell-pack antigen (16-32 units) was used. Usually 20 or more sera from retired breeder rats (generally 6 to 12 months of age) from each colony were tested. Four germfree colonies, 5 caesarian derived barrier maintained (SPF) colonies and 11 conventional colonies were screened. Germfree colonies were negative; however, 3 of 5 SPF colonies were positive, and all 11 conventional colonies were positive. The incidence of rats with antibody in the positive colonies ranged from 17 to $100 \%$ with a mean of $62 \%$. CF antibody titers in the rats ranged between 1:10 (lowest serum dilution tested) and 1:160. In addition to colony reared rats, 43 of $108(39.8 \%)$ sera from wild rats trapped in several dumps ${ }^{3}$ were positive for CF antibody.

\subsection{Virus Isolation}

Efforts were undertaken to isolate the agent in rats responsible for the presence of MHV antibody. The first isolation technique employed was the rat antibody production test (RAP) which is analogous to the mouse antibody production test (MAP) described by Rowe et al. (16) and which is used extensively in our laboratory for detection of adventitious virus contamination in various biologic systems. SPF CD Fischer rats from CRBL (area 13) were selected for virus isolation attempts since this colony had a high incidence of MHV CF reactive antibody and was free of other common indigenous viruses of rats, including Kilham rat virus (KRV), H-I (Toolan), Sendai, and pneumonia virus of mice (PVM). Pools of kidneys, intestines, liver, or lungs were prepared from 5 rats each, and made into $10 \%$ extracts. Each tissue extract was inoculated into 2 or 3 weanling age NL Fischer rats by a combined intranasal $(0.1 \mathrm{ml})$ intraperitoneal $(0.5 \mathrm{ml})$ route, and 28 days later their sera were tested for $\mathrm{MHV}$ CF reactive antibody. In no case did kidney, liver or intestine extracts induce an RAP response; however,

${ }^{3}$ Sera generously supplied by Dr. L. Kilham, Dartmouth Medical School, Hanover, N.H., U.S.A. 
8 of 10 lung pools from 25- and 35-day old rats induced antibody in the RAP test. A strain of virus, designated 8190, was isolated from one of these pools by inoculating 4 litters of rats by the intranasal route and harvesting their lungs after 7 days. A filtrate (0.03 Selas) of this pool, titrated by RAP, induced MHV antibody through a dilution of $10^{-4}$, which was the highest dilution tested. This pool was used as a starting material for the tissue culture passage. This isolate and subsequent virus pools prepared from this isolate were negative for bacterial and mycoplasma ${ }^{4}$ contamination. Lung suspensions and subsequent cell culture pools of RCV were tested for contamination by other adventitious viruses using the RAP and MAP tests. No evidence of contamination and thus no serologie cross relationship was detected for the following viruses: KRV, PVM, H-1

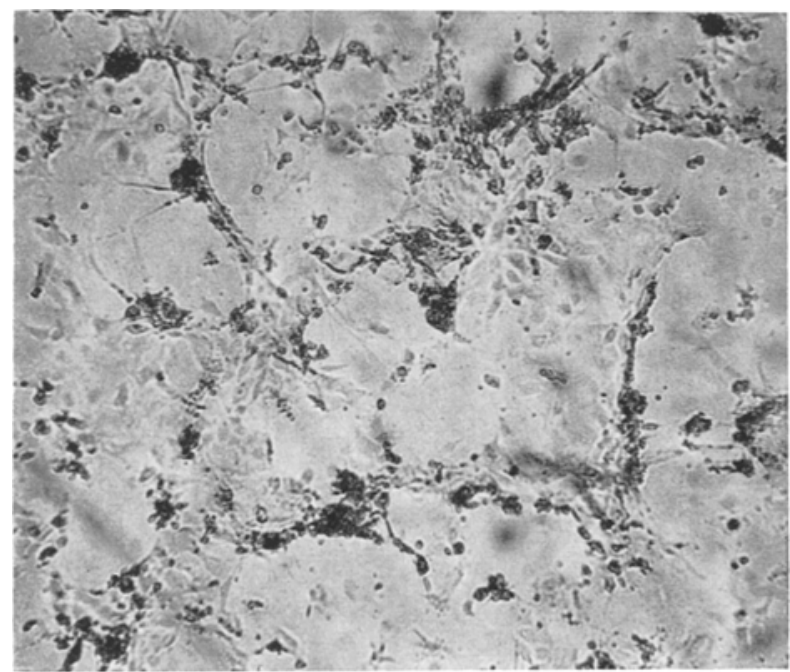

Fig. 1. Cytopathic effects of rat coronavirus in primary rat kidney cell culture 20 hours after inoculation. Unstained, $\times 45$

('Toolan), reovirus type 3, Theiler's GDVII, K virus, polyoma, Sendai, minute virus of mice (MVM), $\mathrm{SV}_{5}$, mouse adenovirus, or lymphocytic choriomeningitis (LCM) virus.

In addition to the RCV isolates obtained from the CRBL rat colony, 2 isolates also were made from lung suspensions of two 6-week old rats from the animal production section of the National Institutes of Health, Bethesda, Md., U.S.A. Isolations were made by the RAP test and directly in cell culture. Tubes of RKCC inoculated with the lung extracts showed typical CPE and were positive for RCV CF antigen on the 6th day.

\subsection{Growth in Cell Culture}

Many different types of rat tissue cultures including both primary and serially maintained lines were tested; however, only primary rat kidney cell culture (RKCC) was found to support the growth of RCV. With low virus dilutions, extensive CPE is seen by 24 hours. Multinucleated giant cells are present, and probably represent the earliest change. The most striking CPE is focal areas

4 Tests were performed by Dr. L. Hayflick, Stanford University, School of Medicine, Stanford, Calif., U.S.A. 
consisting of holes in the cell sheet containing strands of bizarre, irregular, dark cell masses (Figs. 1, 2); these generally represent degenerated giant cells. Many of the cells show a long, thin, beaded cytoplasmic process extending across the hole. The CPE develops and progresses rapidly, and titration endpoints are reached within 3 days. While all isolates produced a CF antigen in RKCC no hemagglutinins were detected in tests using mouse, chicken, human type 0 , guinea pig, or sheep erythrocytes at incubation temperatures of $4^{\circ}, 22^{\circ}$, and $37^{\circ} \mathrm{C}$.

It is noteworthy that the mouse liver cell line, clone NCTC1469, which is highly sensitive to all strains of MHV (6), did not support the growth of RCV virus. Conversely, MHV (A-59 and MHV-S strains) did not produce CPE or replicate in RKCC. Other primary or continuous passage lines not able to support

Fig. 2. Uninfected control culture of primary rat kidney cells. Unstained, $\times 45$

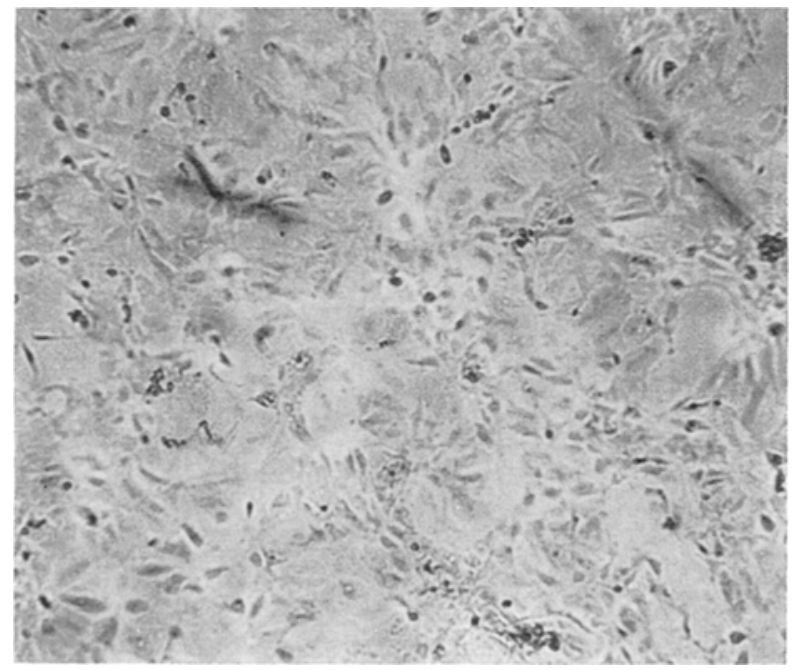

growth of $\mathrm{RCV}$ as measured by $\mathrm{CPE}, \mathrm{CF}$, and in most cases by RAP were: ferret lung, rhesus monkey kidney, human embryonic kidney, human amnion, Balb/c 3T3, hamster embryo, an MSV-transformed Fischer rat cell, NRK (newborn rat kidney), and Fischer strain rat tissue cultures made from embryo, lung, salivary gland, choroid plexus, spleen, and thymus.

\subsection{Pathogenicity}

Intranasal inoculation of newborn Fischer strain rats with RKCC filtrates containing $10^{6} \mathrm{TCID}_{50}$ doses $(0.05 \mathrm{ml})$ results in respiratory distress which becomes apparent in 5 days and which leads to death between the 6 th and 12 th day after infection. Resistance develops rapidly with age. Rats less than 48 hours of age are the most susceptible and experience high morbidity and mortality rates. Rats 7 and 14 days of age develop signs of respiratory disease, but recover within several days and develop normally. Rats 21 days or older show no outward signs of illness. While mortality in day-old Fischer rats was close to $100 \%$ and usually occurred between the 6th and 12th day after infection, mortality in day-old Wistar rats was only 10 to $25 \%$ and usually occurred after the 12 th day. 
Histopathological interpretations were made by Dr. Howard Igel, Children's Hospital of Akron, Akron, Ohio, U.S.A. In tissues from moribund rats which had been inoculated as nowborns, histopathologic lesions were limited to the respiratory system althoug. the infected animals were runted and all their organs were smaller than comparable controls. The lungs of rats sacrificed 4 days after intranasal inoculation $\left(10^{4.9} \mathrm{TCID}_{50}\right)$ showed hyperemia, widespread interstitial pneumonitis (mononuclear) and focal atelectasis. After 8 days, the picture, while similar, also showed diffuse air trapping or compensatory emphysema characterized by dilatation and rounding of alveolar spaces with compression of the septae. A prominent bronchopneumonia probably representing secondary bacterial infection was seen in some animals.

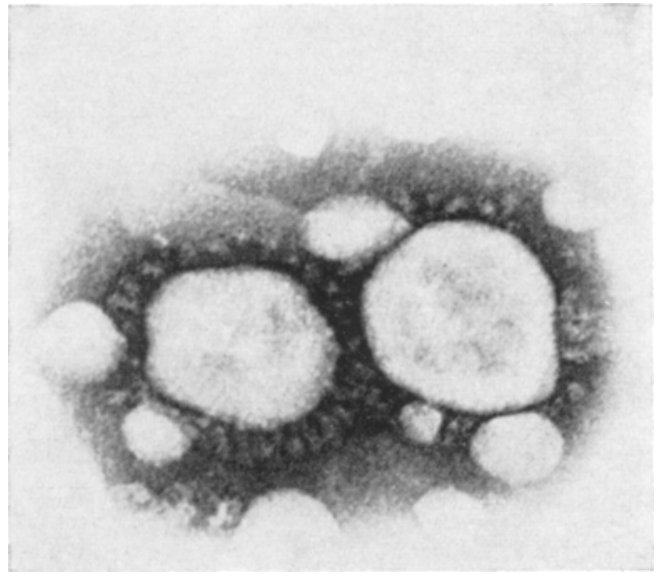

Fig. 3. Two ROV particles, negatively stained, which show the corona of clubshaped projections characteristic of the corona virus group. $\times 200,000$

\subsection{Physical Characteristics}

Cell culture infectivity was completely destroyed by heating at $56^{\circ} \mathrm{C}$ for 30 minutes and by treatment with ether or chloroform. RNA nucleic acid content was suggested by the lack of effect of cytosine arabinoside $(10 \mu \mathrm{g} / \mathrm{ml})$ or actinomycin D $(1 \mu \mathrm{g} / \mathrm{ml})$ on cell culture infectivity as measured by induction of CPE and immunofluorescent stainable antigen. RCV passed through a $100 \mathrm{~m} \mu$ millipore filter (18) with a $2 \log _{10}$ decrease in titer. A $50 \mathrm{~m} \mu$ millipore retained all infectivity.

\subsection{Electron Microscopy}

By electron microscopy, all negatively stained preparations contained morphologically similar virus particles (Fig. 3). These particles were indistinguishable from other viruses belonging to the coronavirus group. The particles were somewhat pleomorphic and possessed a corona of pear or club-shaped surface projections. Measurements of 14 particles were made. The mean longest diameter, including the corona, was $98 \mathrm{~m} \mu(79-118 \mathrm{~m} \mu)$ and the mean smallest diameter was $76 \mathrm{~m} \mu(50-101 \mathrm{~m} \mu)$. The mean length of the spikes of the corona was $17 \mathrm{~m} \mu$ (12-25 m $\mu$ ). Thin section ultramicroscopy (Fig. 4) revealed double membrane particles lacking the corona which were morphologically similar to those described by BECKER et al. (3) for IBV and $229 \mathrm{E}$ coronaviruses. 


\subsection{Serologic Relationship to Mouse Hepatitis Virus}

Because of the close relationship between RCV and MHV, and since all of the serologic studies prior to isolation of RCV used a polyvalent MHV cell-pack CF antigen, it was of interest to compare the serologic relationships between the two viruses. Block CF titrations, in which cell culture antigens were used, tested the four possible combinations of RCV and MHV antigen and antibody (Table 1). While the RCV and MHV antigens (8 units) were nearly comparable for detecting MHV antibody, the RCV antigen was much more sensitive than MHV antigen in detecting RCV antibody but this was overcome by using higher unitage of MHV antigen. Tissue culture neutralization tests revealed a low level cross neutralization (Table 1 ).

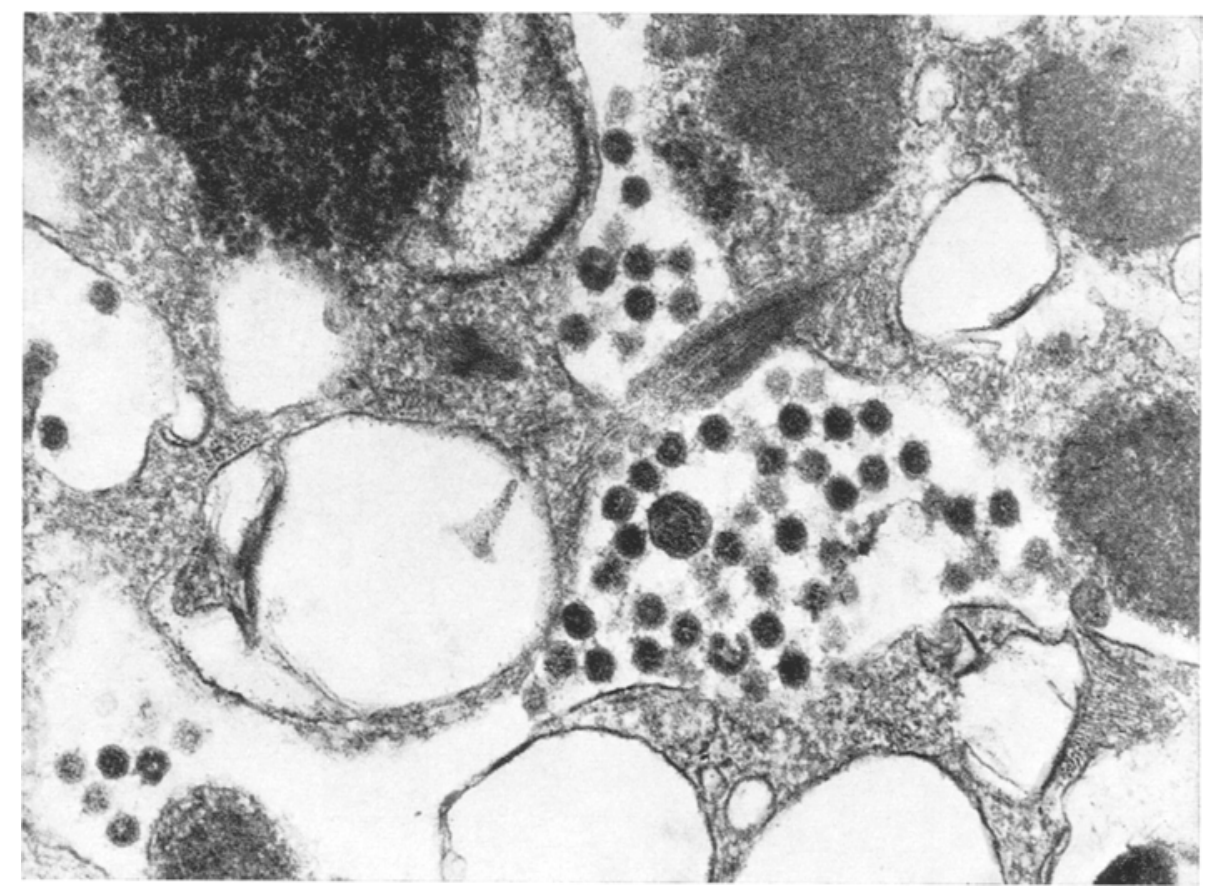

Fig. 4. Section of primary rat kidney cells 40 hours after inoculation with RCV. Particles present within cytoplasmic vesicles have an outer double membrane and lack the corona seen in negatively stained preparations. $\times 63,000$

The sensitivity of RCV and MHV-polyvalent CF antigen for the detection of naturally occurring RCV antibody was compared. A group of 34 rat sera consisting of random samples from each of 3 positive colonies (12, 12, and 10 sera each) were tested at initial 1:10 serum dilutions using $16 \mathrm{RCV}$ and $32 \mathrm{MHV}$ CF antigen units. RCV antigen was about a third more sensitive than MHV, detecting 27 versus 21 positive sera. Also, the RCV antigen gave higher antibody titers in most of the positive sera.

\section{Discussion}

Characterization of the infectious agent isolated from the lungs of normal rats indicated that the agent was a virus and fulfilled all the criteria for belonging to the proposed (1) coronavirus classification group (Table 2). Electron mi- 
croscopic studies revealed a morphology similar to other members of the coronavirus group which include MHV, IBV, and viruses isolated from the upper respiratory tract of humans $(4,9,11)$. The virus, termed rat coronavirus (RCV), was serologically distinct by the RAP test from other viruses found to occur as indigenous virus infections in rodents (rats, mice, and hamsters). The agents

Table 1. Serologic Relationship of $R C V$ and $M H V$ Viruses Demonstrated by Complement Fixation and Neutralization Tests

\begin{tabular}{|c|c|c|c|c|}
\hline \multirow[b]{2}{*}{ Test } & \multirow[b]{2}{*}{ Antigen } & & \multicolumn{2}{|l|}{ Antibody titer } \\
\hline & & & $\begin{array}{l}\text { MHV polyvalent } \\
\text { antiserum } \\
\text { (mouse) }\end{array}$ & $\begin{array}{l}\text { RCV antiserum } \\
\text { (rat) }\end{array}$ \\
\hline \multirow{3}{*}{ CF } & MHV (polyvalent) & 64 units & $320^{1}$ & 320 \\
\hline & & 8 units & 80 & 10 \\
\hline & $\mathrm{RCV}$ & 8 units & 40 & 640 \\
\hline \multirow{2}{*}{ Neutralization ${ }^{2}$} & $\mathrm{MHV}(\mathrm{A}-59)$ & & 640 & 10 \\
\hline & $\mathrm{RCV}$ & & 40 & 2560 \\
\hline
\end{tabular}

1 Reciprocal antibody titer.

2 Neutralization tests employed the cell lines NCTC 1469 for MHV (A-59) and RKCC for RCV. Virus-antibody mixtures (approximately 100 TCID $_{50}$ of $\mathrm{RCV}$ ) were incubated at $37^{\circ} \mathrm{C}$ for 45 minutes and tissue cultures were read for CPE on the 2nd day after inoculation.

Table 2. Properties of Rat Coronavirus

\begin{tabular}{ll}
\hline Natural host & Colony reared rats, wild rats \\
Distribution & U.S.A., England (other countries not tested) \\
Prevalence & $\begin{array}{l}14 \text { of } 20(70 \%) \text { rat breeder colonies ( } 100 \% \text { of conven- } \\
\text { tionally reared colonies) } \\
62 \% \text { of rats within infected colonies have CF antibody } \\
\text { Lungs of rats tested by rat antibody production test } \\
\text { Isolation }\end{array}$ \\
or tissue culture \\
Growth & Primary rat kidney cell culture or lungs of suckling rats \\
Pathology & Interstitial pneumonitis, hyperemia, focal atelectasis \\
Size - Electron microscopy 1 & Variable, approximately 90 mu \\
$\quad$ Filtration & Passes 100 mu but not 50 mu Millipore \\
Essential lipid & Ether and chloroform sensitive \\
Heat sensitivity & Infectivity destroyed at $56^{\circ} \mathrm{C}$ for 30 minutes \\
Nucleic acid type & Apparent RNA content since growth not inhibited by \\
& cytosine arabinoside or actinomycin $\mathrm{D}$
\end{tabular}

${ }^{1}$ Negative contrast technique - projections are included in the diameter of particle.

associated with enzootic bronchiectasis (12) and endemic pneumonia (8) of rats were not available for comparison to RCV; however, the identity of these agents as viruses is not convincing and it has been suggested that they are in fact mycoplasma (5). The virus isolated from the submaxillary glands of rats by AswE et al. (2) is distinguishable from RCV on the basis of different physical properties. 
RCV is serologically related to MHV, a similarity which initiated the present study and led to the isolation of RCV. However, although MHV and RCV are serologically and morphologically related, they are clearly two separate and distinguishable viruses. $\mathrm{MHV}$ and $\mathrm{RCV}$ produce similar $\mathrm{CPE}$, but each in a different cell line which is not reciprocally infected by the other virus. The two viruses differ markedly in their pathogenicity. The MHV complex produces encephalitis and hepatitis in mice and is normally an enteric infection (15), while RCV produces peumonitis in rats, and is almost certainly spread by the respiratory route. While MHV and RCV are related viruses as shown by CF and neutralization tests, McIrtosh et al. (11) showed in an analogous manner that MHV and some of the IBV-like coronaviruses isolated from human respiratory tracts are also related.

A number of technical problems have made it difficult to obtain information on RCV. The widespread prevalence of RCV in rat colonies together with other frequently occurring respiratory viruses of rats, such as Sendai virus and PVM virus (14), have made it difficult to obtain suitable animals needed to carry out routine laboratory procedures, infectivity titrations, production of lung grown virus uncontaminated with other agents, and preparation of monotypic antisera. Inadvertent contamination of rat kidney tissue culture with Kilham rat virus and H-1 virus occurred when rats from a colony harboring these indigenous infections were used for tissue culture. The use of germfree rats circumvented many of these problems; however, even with the use of germfree rats many lots of primary rat kidney tissue culture were observed to undergo a spontaneous CPE which was distinct from that produced by RCV. Recently a virus-like agent has been isolated from one of these degenerating cultures and presently is being studied. This agent is cyclic or seasonal and during periods of high prevalence tissue culture studies with RCV were not possible. In spite of these difficulties it has been possible to work with $\mathrm{RCV}$, but only as the result of routine and extensive monitoring for indigenous virus infections of rat colonies and of tissue cultures for viral contamination. The narrow tissue culture range also presents great difficulties. Of the many tissue culture systems tested, only the rat kidney cell culture system was sensitive, and even this was not sensitive unless the cultures contained a large number of epithelial type cells.

Chronic respiratory disease and rat pneumonia are the most serious diseases affecting aged rats and effectively block attempts by researchers to carry out long term holding experiments using aged rats. A number of agents which have been incriminated in rat pneumonia, might also play a role in the chronic respiratory disease syndrome. These include: pneumonia virus of mice (PVM), Sendai virus, enzootic bronchiectasis "virus", Mycoplasma pulmonis, and several bacterial species, the most important being Pasteurella pneumotropica (5). In addition to these agents it will be important in future investigations to study the potential role of RCV in the syndrome of chronic respiratory disease.

Recent studies by KaPIKIAN et al. (9) suggests that the IBV-like coronavirus isolated from the upper respiratory tract of man may be the etiologic agents of a portion of human respiratory illnesses which occur during the winter. Because of the apparent similarity in organ specificity of the human-IBV viruses and RCV it would appear the RCV may be valuable as a laboratory model system. 


\section{Acknowledgements}

The authors wish to acknowledge the able technical assistance of Miss C. Meyer and Mrs. L. Rodriquez, and thank Dr. Jay Levy for testing the growth of RCV in several lines of tissue culture.

\section{References}

1. Almeida, J. D., D. M. Berry, C. H. Cunningham, D. Hamre, M. S. Hofstad, L. Mallucci, K. McIntosh, and D. A. J. TxRRell: Coronaviruses. Nature (Lond.) 220, $650(1968)$.

2. Ashe, W. K., H. W. Scherp, and R. J. FitzGerald: Previously unrecognized virus from submaxillary glands of gnotobiotic and conventional rats. J. Bact. 90, $1719-1729(1965)$.

3. Becker, W. B., K. MoIntosh, J. H. Dees, and R. M. Chanock: Morphogenesis of avian infectious bronchitis virus and a related human virus (Strain $229 \mathrm{E}$ ). J. Virol. 1, 1019-1027 (1967).

4. Berry, D. M., J. G. Cruickshank, H. P. Chu, and R. J. H. Wells: The structure of infectious bronchitis virus. Virology 23, 403-407 (1964).

5. Brennan, P. C., T. E. Fritz, and R. J. Flyna: Murine pneumonia: A review of the etiologic agents. Lab. Anim. Care 19, 360-371 (1969).

6. Hartley, J. W., and W. P. Rowe: Tissue culture cytopathic and plaque assay for mouse hepatitis viruses. Proc. Soc. exp. Biol. (N.Y.) 113, 403-406 (1963).

7. Hartley, J.W., W.P. Rowe, H.H. Bloom, and H.C.Turner: Antibodies to mouse hepatitis viruses in human sera. Proc. Soc. exp. Biol. (N.Y.) 115, 414-418 (1964).

8. Joshi, N. N., D. G. Dale, and A. C. Blackwood: Etiology of murine endemic pneumonia. Rev. canad. Biol. 24, $169-178$ (1965).

9. Kaptkian, A. Z., J. D. Harvey, JR., S. J. Kelly, J. H. Dees, H. C. Turner, K. MoIntosh, Hyun Wha Kim, R. H. Parrott, M. M. Vincent, and R. M. CHANOCK: Isolation from man of "Avian infectious bronchitis virus-like" viruses (Coronaviruses) similar to $229 \mathrm{E}$ virus, with some epidemiological observations. J. infect. Dis, 119, 282-- 290 (1969).

10. Kaplan, M. M., T. J. Wrktor, R. F. Maes, J. B. Campbell, and H. Koprowski: Effect of polyions on the infectivity of rabies virus in tissue culture: Construetion of a single-cycle growth curve. J. Virol. 1, 145-151 (1967).

11. MoIntosh, K., A. Z. Kapikian, K. A. Hardison, J. W. Hartley, and R. M. CHANock: Antigenic relationships among the coronaviruses of man and between human and animal coronaviruses. J. Immunol. 102, 1109-1118 (1969).

12. Nelson, J. B.: Studies on endemie pneumonia of the albino rat. II. The nature of the causal agent in experimentally infected rats. J. exp. Med. 84, 15-22 (1946).

13. Parker, J. C., R. W. Tennant, T. G. Ward, and W. P. Rowe: Virus studies with germfree mice. I. Preparation of serologic diagnostic reagents and survey of germfree and monocontaminated mice for indigenous murine viruses. J. nat. Cancer Inst. 34, 371-380, (1965).

14. Parker, J. C., J. I. Hercules, and E. von Kafnel: The prevalence of some indigenous viruses of rat and hamster breeder colonies. Bact. Proc. 163 (1967).

15. Rowe, W. P., J. W. HaRtLeY, and W. I. CAPPS: Mouse hepatitis virus infection as a highly contagious, prevalent, enteric infection of mice. Proc. Soc. exp. Biol. (N.Y.) 112, $161-165$ (1963).

16. Rowe, W.P., J. W. HARthex, and R. J. HUEBner: Polyoma and other indigenous mouse viruses, pp. 131-142, In: The Problems of Laboratory Animal Disease, (R. I. C. HaRris, ed.), New York: Academic Press, 1962.

17. Schelr, K., R. J. Huebner, and H. C. Turner: Concentration of complement fixing viral antigens. Proc. Soc. exp. Biol. (N.Y.) 121, $41-46$ (1966).

18. VER, B. A., J. L. MELNICK, and C. WALLIS: Efficient filtration and sizing of viruses with membrane filters. J. Virol. 2, $21-25$ (1968). 